RAND RESEARCH AREAS CHILDREN AND FAMILIES EDUCATION AND THE ARTS ENERGY AND ENVIRONMENT HEALTH AND HEALTH CARE INFRASTRUCTURE AND TRANSPORTATION INTERNATIONAL AFFAIRS LAW AND BUSINESS NATIONAL SECURITY POPULATION AND AGING PUBLIC SAFETY SCIENCE AND TECHNOLOGY TERRORISM AND HOMELAND SECURITY

This fact sheet is part of the RAND Corporation research brief series. RAND fact sheets summarize published, peerreviewed documents.

Headquarters Campus 1776 Main Street P.O. Box 2138 Santa Monica, California 90407-2138

TEL 310.393 .0411

FAX 310.393 .4818

() RAND 2010

\section{Improving the Quality of Care for Dementia}

D ementia is a common problem in older individuals, and very prevalent in those over 85 . But care provided for dementia is poor. Assessing Care of Vulnerable Elders-2 (ACOVE-2), a RAND Health project focused on redesigning primary care practices in order to improve care for elders, was successful in enhancing care for falls and urinary incontinence but not for dementia. Analysis of program results showed that physicians performed better on medical components (e.g., ordering tests) than on counseling and education for dementia patients and their caregivers. Alzheimer's Association chapters provide these kinds of support services, but the medical community and Alzheimer's Association chapters rarely communicate or collaborate.

To address this need, RAND researchers strengthened ACOVE-2 in three ways: Participating primary care physicians were given feedback about their baseline performance, focus groups were conducted to gain provider perspective on unmet needs in managing dementia patients, and the project team worked directly with practices to customize the intervention in order to meet these needs and to improve quality of care. The third component included establishing referral links to local Alzheimer's Association chapters to enhance patient and family education and community services. The improved intervention was pilot tested in two community-based physician practices and evaluated.

Key findings from the evaluation include the following:

- Overall quality of care improved: The percentage of quality indicators that were met rose from 38 percent to 46 percent.

- Assessment of functional status, discussion of the risks and benefits of antipsychotics, and counseling of caregivers significantly improved.

- Quality indicators for cognitive assessment, review of medications, and neurological examinations did not improve.

Before the program, no patients at either site had been referred to the Alzheimer's Association; after the intervention, 17 percent had been referred. Quality scores for the referred patients were higher, and they were more likely to receive counseling about driving, caregiver counseling, and specification of a surrogate decisionmaker.

Results of this pilot program suggest that a quality improvement program specifically focused on dementia care, when coupled with strong linkages to local Alzheimer's Association chapters, is a promising approach to improving the quality of dementia care. 


\section{Office of Congressional Relations | 703-413-1100x5320 | ocr@rand.org | www.rand.org/congress}

This fact sheet was written by Mary E. Vaiana. The RAND Corporation is a nonprofit institution that helps improve policy and decisionmaking through research and analysis. RAND's publications do not necessarily reflect the opinions of its research clients and sponsors. RAND ${ }^{\circledR}$ is a registered trademark.

\section{RAND Offices}

Santa Monica, CA • Washington, DC • Pittsburgh, PA • New Orleans, LA/Jackson, MS • Boston, MA • Doha, QA • Cambridge, UK・ Brussels, BE 
THE ARTS

CHILD POLICY

CIVIL JUSTICE

EDUCATION

ENERGY AND ENVIRONMENT

HEALTH AND HEALTH CARE

INTERNATIONAL AFFAIRS

NATIONAL SECURITY

POPULATION AND AGING

PUBLIC SAFETY

SCIENCE AND TECHNOLOGY

SUBSTANCE ABUSE

TERRORISM AND HOMELAND SECURITY

TRANSPORTATION AND

INFRASTRUCTURE

WORKFORCE AND WORKPLACE
This PDF document was made available from www.rand.org as a public service of the RAND Corporation.

This product is part of the RAND Corporation research brief series. RAND research briefs present policy-oriented summaries of individual published, peerreviewed documents or of a body of published work.

The RAND Corporation is a nonprofit research organization providing objective analysis and effective solutions that address the challenges facing the public and private sectors around the world.

\section{Support RAND}

Browse Books \& Publications

Make a charitable contribution

For More Information

Visit RAND at www.rand.org

Explore RAND Health

View document details
Limited Electronic Distribution Rights

This document and trademark(s) contained herein are protected by law as indicated in a notice appearing later in this work. This electronic representation of RAND intellectual property is provided for noncommercial use only. Unauthorized posting of RAND PDFs to a non-RAND Web site is prohibited. RAND PDFs are protected under copyright law. Permission is required from RAND to reproduce, or reuse in another form, any of our research documents for commercial use. For information on reprint and linking permissions, please see RAND Permissions. 